\title{
THE INFLUENCES OF DIFFERENT DEGREES OF INTERSPECIFIC HYBRIDISATION WITH SENECIO SQUALIDUS ON THE FREQUENCY OF TWO MORPHS OF SENECIO VULGARIS
}

\author{
PETER HULL \\ Department of Biology, University of Strathclyde, Glasgow GI IXW
}

Received 20.vii.75

\begin{abstract}
Summary
In 3 successive years samples of Senecio vulgaris L., from different populations were classified according to their capitulum type. Two areas in Central Scotland were chosen, six populations being taken from an area were Senecio squalidus $\mathrm{L}$. grows in relative abundance and nine from an area where plants of this species are rarely found. This allowed the investigation of changes in the relative frequency of the alleles $T_{r}$ and $T_{n}$ controlling capitulum type in these polymorphic populations. The possibility that the $T_{r}$ allele is being introduced into the populations of $S$. vulgaris by hybridisation with $S$. squalidus is investigated. It is concluded that this is a more probable explanation than the alternative possibility that the observed changes in allelic frequency are due to differences between the fitnesses of the radiate, intermediate and non-radiate capitulum morphs which are found in the populations.
\end{abstract}

\section{INTRODUCTION}

The evidence that the occurrence of the plants of the radiate $\left(\mathcal{T}_{r} \mathcal{T}_{r}\right)$ capitulum type in populations of Senecio vulgaris L. (chromosome number, $2 n=40$ ) may be a result of limited interspecific hybridisation with Senecio squalidus L. $(2 n=20)$, followed by backcrossing, has been discussed in several papers (e.g. Hull, 1974a, 1975; Richards, 1975). Several species of Senecio found in the British Isles are capable of hybridisation (Gibbs, 1971), and the occurrence of a natural hybrid of $S$. vulgaris and $S$. squalidus, producing many offspring with chromosome number $2 n=40$, has been reported (Crisp and Jones, 1970).

Sterile interspecific hybrids between $S$. squalidus and $S$. vulgaris (Harland, 1955), self-fertile hybrids, $2 n=60$ (Lousley, 1955; Rosser, 1955) and backcrosses to $S$. squalidus (Gibbs, 1971), have been produced experimentally.

The facts that $S$. squalidus is extending its range in the British Isles and that the radiate morph of $S$. vulgaris tends to appear in an area only after $S$. squalidus has become established, have been noted by a number of authors, comparing the published distribution maps of $S$. squalidus (Perring and Walters, 1962) with that of radiate morph of $S$. vulgaris (Perring and Sell, 1968).

Evidence of gene flow, due to interspecific hybridisation, from $S$. squalidus to $S$. vulgaris based on observed clines in phenotypic characters is available from two sources. In the first, the distribution of esterase isozymes of different electrophoretic mobility (located by acrylamide gel electrophoresis) has been studied in several populations of plants of the genus Senecio in Central Scotland (Hull, 1974b). The distribution of enzymes from plants of 
$S$. vulgaris collected from an area where $S$. squalidus is common (Kent, 1965), showed more resemblance to that within the local population of $S$. squalidus than did the distribution of enzymes from a sample of $S$. vulgaris plants from an area where $S$. squalidus is very rare. Moreover, within both areas, the enzyme pattern from a sample of radiate plants more closely resembled that of the sample of $S$. squalidus plants than did that of the non-radiate plants from the same area.

In the second study (Monaghan and Hull, 1975), similar clines in leaf length, leaf breadth and leaf shape in plants collected from the same areas provided further data which could be interpreted as evidence of gene flow from $S$. squalidus to $S$. vulgaris.

In order to investigate the possibility that, for any given population of $S$. vulgaris, the frequency of the radiate morph might be directly dependent on the amount of interspecific hybridisation and thus on the number of $S$. squalidus plants growing at that location, it was decided to compare the changes in frequency of the $T_{r}$ allele in polymorphic populations of $S$. vulgaris taken from two areas, one in and around Edinburgh, where $S$. squalidus had earlier been reported as growing in eight identifiable locations (Kent, 1965), the other in Glasgow where $S$. squalidus was rare; that is, no colonies of $S$. squalidus had previously been noted (Kent, 1965), but occasional individual plants were found by the author in 1972 and subsequently. This comparison was made by taking a sample of plants from several uniform populations within each area (six in the case of the Edinburgh area, nine in the case of the Glasgow area) in 1972, 1973 and 1974, and comparing the rate of change of the $T_{r}$ allele between the two areas.

\section{Methods of SAMPling, Results AND ANAlysis}

Samples of plants were taken from the 15 populations by marking out the chosen area of ground into a series of rectangles, $12.5 \times 4$ metres and classi-

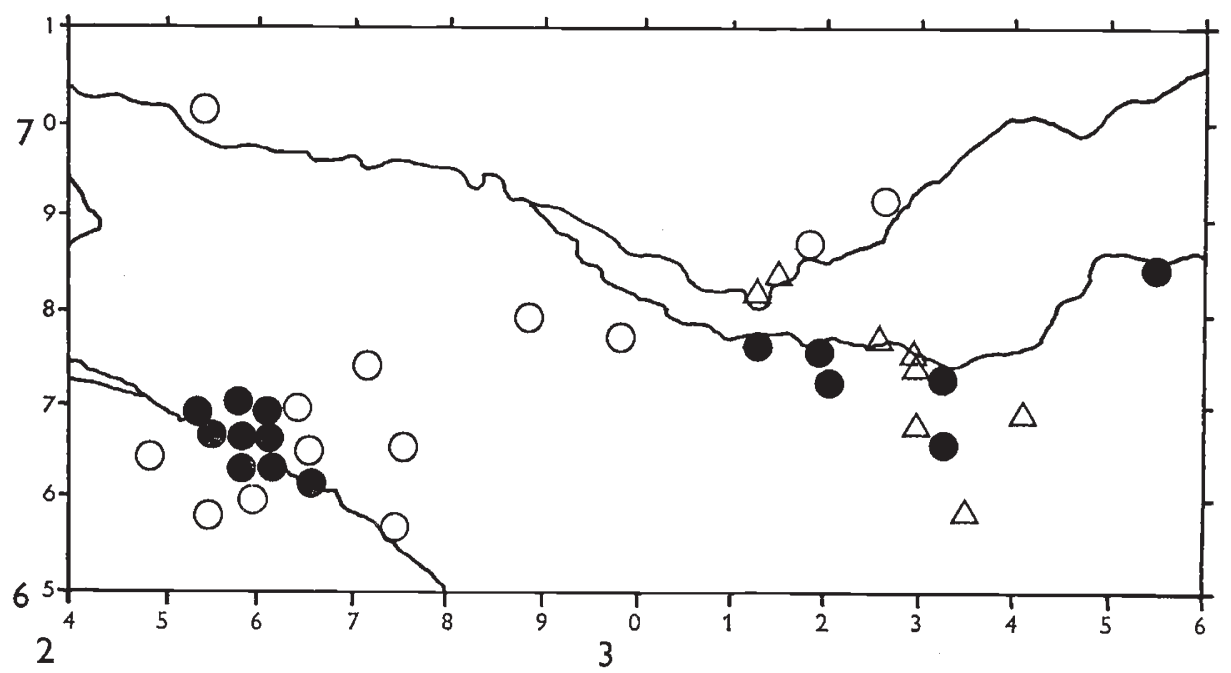

FIG. 1.-Approximate location of polymorphic populations (black circles) of Senecio vulgaris; populations consisting of the non-radiate morph only (open circles) and populations of $S$. squalidus (triangles). 
fying the plants according to their capitulum types as $R$ (radiate, $T_{r} T_{r}$ ); $I$ (intermediate, $\mathcal{T}_{r} \mathcal{T}_{n}$ ) or $\mathcal{N}$ (non-radiate, $\mathcal{T}_{n} \mathcal{T}_{n}$ ). The genetic control of capitulum type in this species by a single, incompletely dominant locus, the $T$ locus, has been established by data from several breeding experiments (e.g. Trow, 1912). A sketch map showing the approximate location of the 15 polymorphic populations, as black circles, other, non-polymorphic populations of $S$. vulgaris (Hull, 1974a, 1975) as open circles and the sites where $S$. squalidus was found (Kent, 1965) as triangles, is given in fig. 1. The exact methods of sampling used have been detailed previously (Hull, $1974 a$ ). The frequency of the $T_{r}$ allele was then calculated for each population in each year; these frequencies are plotted in fig. 2 together with the total number of plants in each sample. An unweighted analysis of covariance of allelic frequency on year was then carried out as summarised in table 1, where again each population is identified by an eight-figure national grid

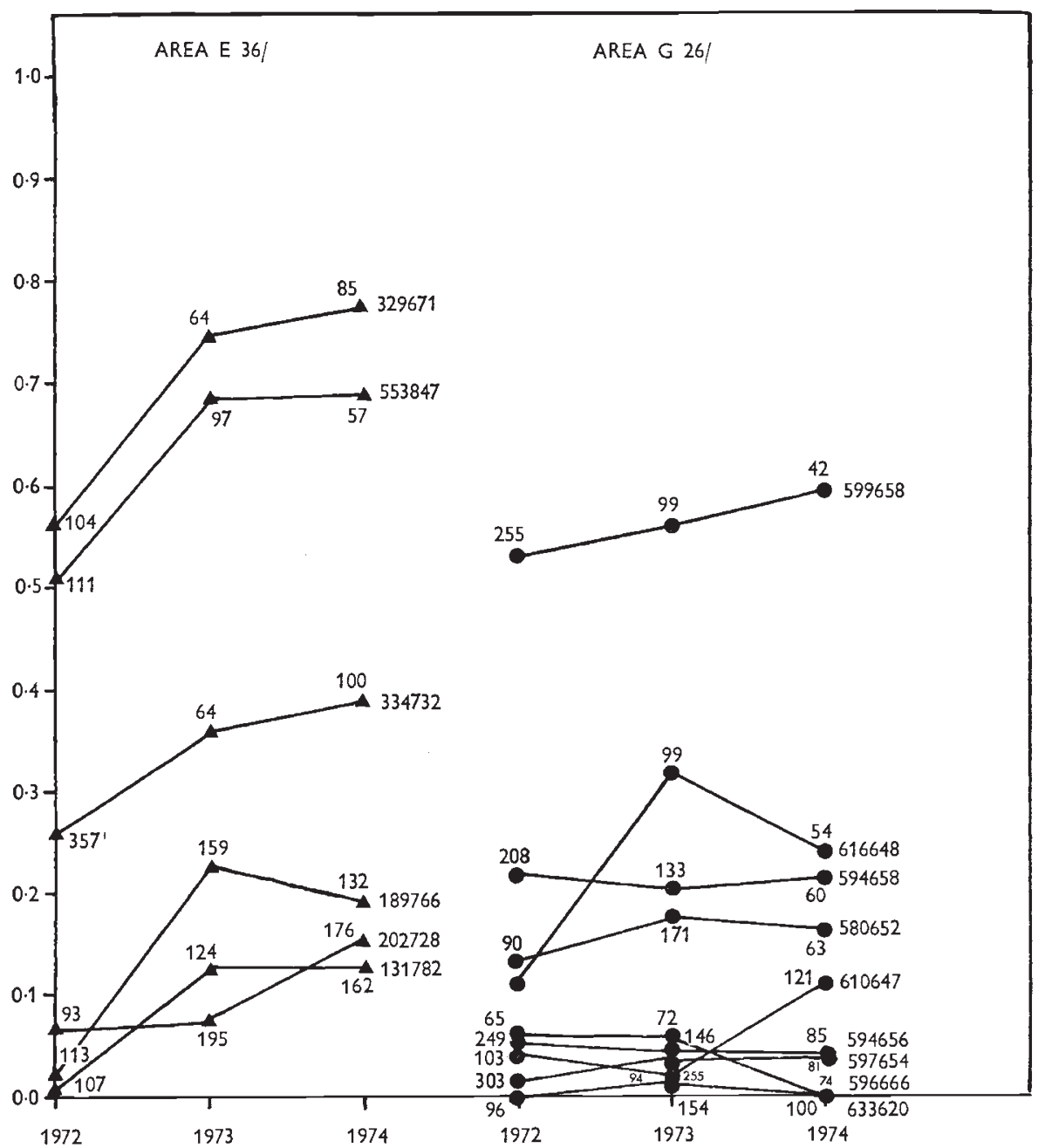

Fig. 2.-Mean frequencies of the $T_{r}$ allele in the 15 populations in the 3 successive years. 
TABLE 1

Comparison of regression of frequency of the $\mathrm{T}_{r}$ allele on year between populations, within areas, and between the Edinburgh and Glasgow areas

\begin{tabular}{|c|c|c|c|c|c|}
\hline \multirow{2}{*}{$\begin{array}{l}\text { Edinburgh } \\
\text { Population }\end{array}$} & \multirow[b]{2}{*}{$\mathrm{b}_{\mathbf{Y}} \mathbf{x}$} & \multicolumn{2}{|c|}{ Due to regression } & \multicolumn{2}{|c|}{$\begin{array}{l}\text { Deviations from } \\
\text { regression }\end{array}$} \\
\hline & & d.f. & S.S. & d.f. & S.S. \\
\hline $36 / 329671$ & +0.109 & 1 & 0.023762 & 1 & 0.004593 \\
\hline 553847 & +0.093 & 1 & 0.017113 & 1 & 0.005221 \\
\hline 334732 & +0.064 & 1 & $0 \cdot 008192$ & 1 & 0.000726 \\
\hline 202728 & $+0 \cdot 044$ & 1 & $0 \cdot 003872$ & 1 & 0.000817 \\
\hline 189766 & +0.090 & 1 & 0.016025 & 1 & 0.009361 \\
\hline 131782 & +0.061 & 1 & $0 \cdot 007321$ & 1 & 0.002360 \\
\hline \multicolumn{2}{|l|}{ Total } & 6 & $0 \cdot 076285$ & 6 & 0.023078 \\
\hline \multirow{4}{*}{\multicolumn{2}{|c|}{$\begin{array}{l}\text { Source of variation } \\
\text { Separate regression lines } \\
\text { Joint regression slope } \\
\text { Difference in slopes }\end{array}$}} & d.f. & S.S. & M.S. & $F$ ratio \\
\hline & & 6 & 0.076285 & $0 \cdot 012714$ & - \\
\hline & & 1 & 0.070395 & 0.070395 & $F_{6}^{1}=18.30$ \\
\hline & & 5 & 0.005901 & 0.001180 & $\mathrm{~F}_{6}^{5}<1$ \\
\hline \multicolumn{2}{|l|}{ Residual } & 6 & $0 \cdot 023078$ & $0 \cdot 003846$ & - \\
\hline \multirow[b]{2}{*}{$\begin{array}{l}\text { Glasgow } \\
\text { Population }\end{array}$} & & \multicolumn{2}{|c|}{ Due to regression } & \multicolumn{2}{|c|}{$\begin{array}{l}\text { Deviations from } \\
\text { regression }\end{array}$} \\
\hline & $b_{\mathbf{X} . \mathbf{y}}$ & d.f. & S.S. & d.f. & S.S. \\
\hline $26 / 599658$ & +0.029 & 1 & $0 \cdot 001682$ & 1 & 0.000017 \\
\hline 594658 & $-0 \cdot 002$ & 1 & $0 \cdot 000008$ & 1 & 0.000171 \\
\hline 580652 & $+0 \cdot 017$ & 1 & 0.000578 & 1 & $0 \cdot 000417$ \\
\hline 616648 & +0.062 & 1 & 0.007688 & 1 & $0 \cdot 012881$ \\
\hline 596666 & $-0 \cdot 031$ & 1 & 0.001922 & 1 & 0.00041 \\
\hline 594656 & $-0 \cdot 005$ & 1 & $0 \cdot 000045$ & 1 & 0.000014 \\
\hline 610647 & $+0 \cdot 032$ & 1 & $0 \cdot 002048$ & 1 & 0.001667 \\
\hline 597654 & $+0 \cdot 010$ & 1 & $0 \cdot 000200$ & 1 & 0.000043 \\
\hline 633620 & $+0 \cdot 000$ & 1 & 0.000000 & 1 & 0.000241 \\
\hline \multicolumn{2}{|l|}{ Total } & 9 & $0 \cdot 014171$ & 9 & $0 \cdot 015868$ \\
\hline \multicolumn{2}{|c|}{ Source of variation } & d.f. & S.S. & M.S. & $\mathrm{F}$ ratio \\
\hline \multicolumn{2}{|c|}{ Separate regression line } & 9 & 0.014171 & $0 \cdot 001575$ & - \\
\hline \multicolumn{2}{|c|}{ Joint regression slope } & 1 & 0.002813 & 0.002813 & $\mathrm{~F}_{9}^{1}=1.59$ \\
\hline \multicolumn{2}{|c|}{ Difference in slopes } & 8 & $0 \cdot 011358$ & $0 \cdot 001419$ & $\mathrm{~F}_{8}^{8}<1$ \\
\hline \multicolumn{2}{|c|}{ Residual } & 9 & $0 \cdot 015868$ & 0.001763 & \\
\hline
\end{tabular}

reference. It will be seen that the differences between slope of the six different populations within the Edinburgh area are not significant $\left(F_{6}^{5}=0 \cdot 307\right)$. Similarly, the regression of allelic frequency on years in the nine populations in the Glasgow area are also homogeneous $\left(\mathrm{F}_{9}^{8}=0 \cdot 805\right)$. It is therefore possible to calculate a joint regression of gene frequency on year for the six Edinburgh regions and this is found to have a significant positive gradient $\left(\mathrm{F}_{6}^{1}=18.30 ; 1 \% \mathrm{~F}_{6}^{1}=12 \cdot 25\right)$. On the other hand, the joint regression for the nine Glasgow regions has a slope not significantly different from zero $\left(\mathrm{F}_{6}^{\mathbf{1}}=1 \cdot 59 ; 5 \% \mathrm{~F}_{6}^{\mathbf{1}}=5 \cdot 12\right)$.

\section{Discussion}

The fact that the increase in the frequency of the $T_{r}$ allele is very much greater in the Edinburgh area than in the Glasgow area (see fig. 2 and 
table 1) might be due either to the fact that the fitnesses of the three genotypes are different in the two areas, or that hybridisation with $S$. squalidus is taking place to a greater extent in the Edinburgh area, with consequent gene flow and an expected increase in frequency of all alleles (including the $T_{r}$ allele), derived from $S$. squalidus.

There is in fact a remarkable stability in allelic frequency within the populations from year to year (fig. 2). The samples taken may be part of much larger populations in each case, or seeds may persist in the soil for more than 1 year, thus smoothing out any fluctuations in allelic frequency.

Evidence has been presented (Monaghan and Hull, 1975) that continued hybridisation of $S$. squalidus with $S$. vulgaris has resulted in an alteration of leaf shape of plants of $S$. vulgaris in these two areas in Central Scotland, so that these plants now show a greater resemblance to $S$. squalidus in this characteristic. Further than this, it was suggested that mean leaf size may eventually show an increase in these populations of $S$. vulgaris as a result of gene flow from $S$. squalidus, which has larger leaves than $S$. vulgaris, but that the initial result of hybridisation is a reduction of both mean leaf length and mean leaf breadth in hybrid populations, perhaps due to chromosomal imbalance in the immediate hybrids. This conclusion was based on a comparison of leaf characters of radiate and non-radiate plants, within populations, the radiate plants being smaller.

Other measurements of vegetative and reproductive vigour of the radiate and non-radiate morphs of $S$. vulgaris have been made under conditions of controlled plant growth (Richards, 1975). He confirms the lack of vegetative vigour of radiate plants; studying leaf size it was found that the leaves of non-radiate plants grew to a greater size in a shorter period of time than did those of radiate plants. Plants with capitula of the intermediate type had the smallest and slowest growing leaves of all. Furthermore, non-radiate plants reached their maximum height in less than half the time required by radiate plants. Intermediate plants were not only much smaller at flowering, but their overall growth rate was again slowest of all. It also appeared that a greater proportion of non-radiate seed germinated than radiate or intermediate and that its germination was more rapid. Similarly, non-radiate plants flowered earlier, and a greater percentage of the total non-radiate plants finally produced flowers than that of the radiate or intermediate plants.

Against all these findings of the general superiority of non-radiate plants is the suggestion (Richards, 1975), from a preliminary experiment, that under conditions of very high density of growth (one plant to $4 \mathrm{~cm}^{2}$ ), non-radiate plants developed on average one capitulum per plant whilst radiate plants developed an average of six fertile capitula. It might be thought that plants growing naturally under such conditions of extreme overcrowding and producing so few seeds per plant would make only a small contribution to the total quantity of seed produced by the $S$. vulgaris populations.

The radiate plants appear, from a variety of data, to be smaller and to show slower development for almost all components of vegetative vigour and reproductive fitness which have been examined. There is no evidence of heterosis in fitness or vegetative characteristics of plants of intermediate capitulum type. Also, for all the vegetative characteristics examined there appear to be clines in the population means from the $S$. squalidus population through the hybridised $S$. vulgaris populations to the unhybridised populations of $S$. vulgaris. It appears unlikely that all these characteristics would be 
affected by natural selection, due to environmental differences between the Edinburgh and Glasgow areas, or that all are closely linked to some characteristic that is so influenced. Thus is appears that the factor most likely to have influenced the present distribution of all the vegetative and floral characteristics studied in $S$. vulgaris populations in Central Scotland is greater interspecific hybridisation with the related species, $S$. squalidus in the Edinburgh area than in the Glasgow area, rather than selection in favour of radiate plants in the Edinburgh area, because of some undefined environmental difference between the two areas.

\section{ReFERENCES}

CRISP, P., AND JONES, B. M. G. 1970. Senecio squalidus L., S. vulgaris L., and S. cambrensis Rosser. Watsonia, 8, 47-48.

GIBBS, P. E. 1971. Studies on synthetic hybrids of British species of Senecio: 1. Senecio viscosus L. $\times$ S. vulgaris L. Trans. Bot. Soc. Edinb., 41, 213-218.

harland, s. c. 1955. Two new Senecio hybrids. Proc. Bot. Soc. Br. Isl., 1, 260-261.

HULL, P. 1974a. Differences in esterase distribution detected by electrophoresis as evidence of continuing interspecific hybridisation in the genus Senecio, Ann. Bot., 38, 697-700.

HULl, P. 1974b. Self-fertilisation and the distribution of the radiate form of Senecio vulgaris L. in Central Scotland. Watsonia, 10, 69-75.

HULL, P. 1975. Selection and hybridisation as possible causes of changes in the frequency of alleles controlling capitulum type in Senecio vulgaris L. Watsonia, 11, 27-35.

KENT, D. H. 1965. Senecio squalidus L. in the British Isles. 8. The recent spread in Scotland. Glasg. Nat., 18, 407-408.

Lousley, J. E. 1955. The British flora during 1954. Nature, 75, 200-202.

MONAGHAN, J. L., AND HULL, P. 1975. Differences in vegetative characteristics among four populations of Senecio vulgaris L. possibly due to interspecific hybridisation. Ann. Bot., 39, 327-334.

PERRING, F. H., AND SELL, P. D., eds. 1968. Critical Supplement to the Atlas of the British Flora. Nelson, London.

PERRING, F. H., AND WALTERS, s. M., eds. 1962. Atlas of the British Flora. Nelson, London. RICHARDS, A. J. 1975. The inheritance and behaviour of the rayed gene complex in Senecio vulgaris. Heredity, 34, 95-104.

ROSSER, E. M. 1955. A new British species of Senecio. Watsonia, 3, 228-232.

TROW, A. H. 1912. On the inheritance of certain characters in the common groundsel, Senecio vulgaris L., and its segregates. 7. Genet., 2, 239-276. 